\title{
The State of the HIV Epidemic in Latin America and the Caribbean: Policy Recommendations
}

\author{
Juan J. DelaCruz \\ Department of Business and Economics, Lehman College - CUNY \\ 250 Bedford Park Blvd West, CA 379, Bronx, NY 10468, USA \\ Tel: 1-71-8960-8159Ｅ-mail: Juan. DelaCruz2@lehman.cuny.edu
}

Received: January 19, 2011 Accepted: February 10, 2011 doi:10.5539/gjhs.v3n2p56

\begin{abstract}
The objective of this paper is to obtain estimates of the effect of HIV prevalence on economic performance in selected economies of Latin America using a panel regression to identify plausible interventions to fight the epidemic in the region and ameliorate the negative effect of this epidemic on human capital accumulation. Due to the suspicion that either all variables of interest are endogenous, or the explanatory variables are mainly lagged variables, this analysis requires the construction of an econometric device to model multivariate time series. Even though, the epidemic remains at relative low levels compared with other countries and seemingly has not caused harm to the economy, there are worrisome signs showing the potential risk of not taking the proper course of action to make sure that the HIV epidemic would not get out of control as has occurred in others part of the world.
\end{abstract}

Keywords: HIV, Economic growth, Human capital, Latin America

\section{Introduction}

Health is a multi-dimensional notion that is defined as the absence of physical pain, physical disability, or a condition that is likely to cause death. It also represents emotional well-being and leads to a satisfactory social functioning. Health status varies across countries, or even across regions, and its determinants are still poorly understood. Good health improves the stock of human capital and promotes higher levels of productivity, positively affecting potential output. A healthy individual may also earn higher wages, which in fact raises the standards of living and provides better access to health services, therefore causing positive feedback effects (DelaCruz, 2010).

The lack of health stands for the opposite and only few medical conditions, such as the HIV infection, have had a meaningful effect on economic performance. Whether the HIV/AIDS epidemic represents a threat to a country's economic performance in Latin America is still an empirical question in the existing literature. There seems to be an absence of consensus among social scientists on the actual economic effects of this illness as well as on how to implement proper interventions to fight its burden. It certainly poses great challenges for policy makers and civil society to design cost-effective strategies to overcome this problem (DelaCruz, 2010).

In addition, the nature of this epidemic makes it even more difficult to identify a common pattern explaining the elements or conditions under which some populations are more vulnerable than others to this public health problem. The HIV/AIDS epidemic has manifested itself in different forms across countries and has varied consistently over time, transiting from heavily concentrated among high-risk groups to be generalized, so to speak more equally prevalent among men and women, closing the gap of male to female ratio.

In our theoretical model, economic activity establishes the path of the epidemic over time and across countries, but also, there is a possibility of a reverse causation or simultaneity due to the fact that the some factors leading to economic development are also important in the HIV epidemic. The emerging literature on HIV states that the determinants of this illness at the country level are manifold and can be influenced by certain behaviors such as the percentage of circumcised population in a country and the degree of fractionalization within a society (DelaCruz, 2010). Other well-identified controllers commonly used to analyze the HIV epidemic are the share of urban population, access to health services, political risk or instability and net migration index.

Also, some groups are at higher risk than others are. Example of these groups are commercial sex workers, their clients, injecting drug users, men having sex with men and those who acquired other sexually transmitted 
diseases. By the same token, those who are considered vulnerable such as women, migrant workers, refugees, tourists and young people in general are highly susceptible to be infected with the HIV virus. Finally, religious constraints on sexuality may have consequences for the diffusion of sexually transmitted diseases.

The paper aims to quantify the epidemic's effect on economic performance in selected countries of Latin America using a panel regression, which will allow us to capture changes in health capital derived from the HIV infection across countries and over time. This study represents a meaningful starting point in the recognition of the interplay between the HIV outbreak and the economy in the area under consideration as well as will provide insight of its current state. Our findings will help identify the role of domestic institutions and will propose more effective and efficient strategies to deal with the disease.

This manuscript is organized as follows: section 2 reviews the literature, section 3 provides a succinct diagnosis of the HIV epidemic and an explanation of the state of health services in the region, highlighting the importance of innovative prevention and behavior change interventions. Section 4 explains our sources of data and the rationale for utilizing a panel regression to better understand the effects of the HIV epidemic within selected economies during the late 1990's and early 2000's. It also depicts the results of our regression. Section 5 presents a digression on policy suggestions derived from our findings and the conclusions are presented in the final section.

\section{Review of literature}

The vast literature on the economic effect of HIV/AIDS has focused on African countries and usually starts with the analysis of its socio-demographic impact in order to determine the path of the disease and to assess whether or not the illness represents a threat to economic growth (World Bank, IMF, UNAIDS). A major tradition in modeling HIV/AIDS epidemics has been the use of back-calculations techniques in developing countries (Chin and Lwanga, 1991; Schwartlander, 1999). Some studies have tried to account for the effect of different sources of uncertainty on the trajectory of the epidemic (Salomon, 2001; Salomon, 2002). Based upon these calculations, several theoretical attempts have been made with the intention of explaining and quantifying the burden of HIV/AIDS in economic growth (Haacker, 2004; Bloom, 1997; Robalino, 2002; McDonald, 2004, DelaCruz, 2009), especially in those cases where the illness has shown evident devastating results, as seen in many countries in Sub-Saharan Africa, where prevalence of HIV/AIDS is relatively high. Moreover, some countries with low HIV prevalence have transitioned to a high level status when their governments did not take the necessary measures to stop the progress of the disease as occurred in Indonesia and Nepal (Robalino 2002).

The impact of HIV/AIDS in North Africa, Asia or Latin America on sensitive variables related to economic growth might be significant. Although middle- and low-income countries are dealing with a broad HIV/AIDS epidemic and not much information is known or at least the results provided are not conclusive (Dixon, 2001), most of the time the lack of reliable sources of information, miscalculation or inaccurate recording keep governments and private agents from playing a more decisive role in implementing policy measure to fight the adverse effects.

It also seems that the existing literature on the effect of HIV/AIDS on economic performance has elicited mixed outcomes: some studies show that the AIDS epidemic has had an insignificant effect on the growth rate of per capita income, with no evidence of reverse causality (Bloom, 1997); some other scholars point out that HIV reduces economic growth and increases poverty, which in turn accelerates the spread of HIV (Cuddington, 1993; Cuddington, 1994; Bonnel, 2000), and finally other social scientists indicate that in countries where the prevalence of HIV is relatively low the impact of the epidemic conforms to 'normal' expectations, but when the prevalence of the epidemic is relatively high the macroeconomic impact is unclear (Dixon, 2001; McDonald, 2004).

\section{Health markets and the state of the epidemic in Latin America}

Health promotion and disease reduction are two important development goals to achieve human and social potentials, and the key issue lies on overcoming income disparities as well as on the effectiveness and efficiency of health care delivery systems for more than 500 million people across Latin America (Franko, 2007). This health crisis of unknown proportions has contributed to an uncertain outlook of the magnitude and degree of response regarding the HIV/AIDS crisis in the region. Uncertainty has arisen from unreliable surveillance efforts in most of these countries, the suspicion of underreported AIDS deaths, a wave of concurrent business cycles all over Latin America, a mismatch in the market forces for health services and the lack of political leadership in health promotion. Furthermore, when health policy reactions have taken place across these countries, the implemented strategies have yielded uneven results across their own boundaries. For instance, while countries like Cuba, Brazil, Mexico and Costa Rica have shown signs of improvements in their local epidemics, others 
have fallen short from the expectations and HIV prevalence has increased substantially over time, as happened in The Bahamas, Haiti and Guyana.

In addition, Latin America experienced the most severe macroeconomic fluctuations throughout the 1980's and 1990's, coinciding with the early stage and peak of the worldwide HIV epidemic crisis. The strength of the business cycles has undermined the ability of their health systems to manage this public health problem on time and diminished their chances to channel monetary and human resources to properly address its potential effects in the overall economic system. The real effects of the HIV epidemic have become more apparent after the second half of the 1990's and on.

Figure 1 shows that important gains in per capita income have occurred worldwide during the past 50 years, with the only exception of Sub-Saharan Africa where standards of living have shown signs of stagnation between 1960 and 2000. The most dynamic areas of growth during the this period are East Asia/Pacific showing an increase of $330 \%$ in their per capita gross domestic products followed by the Middle East/North Africa and South Asia, both with increments of more than $150 \%$ during this period. A sustained and strong growth characterized North America's economic performance, where income per capita rose to $\$ 31,761$ from $\$ 12,378$, more than $150 \%$ as to 2000 . In Europe and Central Asia region , per capital GDP jumped from $\$ 6,813$ to $\$ 13,864$. Latin American's economic performance is the second least dynamic regions Standards of living just about doubled from $\$ 3,419$ to $\$ 6,865$.

By the same token, figure 2 also reveals that the East Asia/Pacific area, the Middle East/North Africa region and South Asia has shown significant expansion in life span with gains of almost 20 years between 1960 and 2000 . Although improvements in health status have occurred in Latin America over the past decades, health systems are still characterized by an excessive demand over an insufficient supply as well as by the lack of resources, both monetary and human. Several pathologies remain as leading causes of high morbid-mortality rates and among them the region struggles with infectious diseases such as HIV/AIDS, TB and certain chronic-degenerative diseases as well as a high prevalence of maternal and infant mortality ratios.

$<$ Figure 1 and 2>

Some of the common problems in the Latin American region are severe poverty, food shortages, lack of water and sanitation, insufficient housing and gender discrimination. Low educational attainments and a relaxed environmental legal structure represent an important constraint in development plans. Also a weak regulation of pharmaceutical contributes to the growing problem of microbial resistance to antibiotics . Suarez (2000) found out that health systems in Latin America tend to be highly regressive, where taxes, contribution to social security and out-of-pocket expenditures are the main sources of revenues and financing.

As of 2008, the Joint United Nations Program on HIV/AIDS (UNAIDS) reported an estimated 170,000 new infections in Latin America, bringing the number of people living with HIV to an estimated 2 million, more than those living with the disease in the United States, Canada, Japan and the United Kingdom combined. Although this is a big number, prevalence in the region is $0.6 \%$ and is considered a low-level and concentrated epidemic (see figure 3 below). Its evidence is supported by a substantial amount of sero-surveys among key populations that has been conducted in the past couple of years. While the magnitude of the HIV infection ratios is small compared to those in other parts of the world, such as Sub-Saharan Africa, the transmission patterns have moved slowly from marginalized groups toward the general population. So far, no country in Latin America has experienced a decrease in its HIV prevalence during the last decade, raising questions on possible increases over the coming years and the ability of governments and institutions to control a major epidemic.

The epidemic is mainly driven by sexual intercourse and the rate of transmission among men is higher than for those among women, however the male to female ratio, the number of men per women living with the HIV infection, is sharply declining compared to the levels experienced in the early 1990's. There are approximately 2 million people living with HIV/AIDS in Latin America as of 2008 and the proportion of adults aged 15-49 who were living with HIV/AIDS during this year within our sample of countries is $0.8 \%$ with a standard deviation of 0.7 , slightly above the global prevalence threshold, yet far away from the average percentage exhibit in Sub-Saharan Africa (see Appendix 1). Guyana shows the highest HIV prevalence in our illustration and Nicaragua the lowest. Although Trinidad and Tobago and The Bahamas have a greater exposure to the epidemic, there is not enough socio-economic information to include them in this study.

$<$ Figure 3>

There are several groups affected by the epidemic in greater extend than others. Men who have sex with men (MSM) account for the largest share of infections in Latin America and mixed messages can be found. In Peru 
and Mexico the fact that the epidemic is driven by MSM is openly acknowledged, whereas in Guatemala the government claims that is primarily heterosexual but is suspected to be otherwise. Other vulnerable groups are sex workers who represent a major factor in the spread of the disease, particularly in El Salvador, Ecuador, Bolivia and Guatemala, and injecting drug users, especially in those countries that have transited from dictatorships to democracies like Argentina, Brazil, Paraguay and Uruguay. Migration has also contributed to the spread of the disease with an important share, even though its links with domestic rates of HIV infection has not been very well documented.

The Caribbean remains as the second area in the world with the highest adult HIV prevalence with Haiti, The Bahamas, Jamaica, Trinidad and Tobago and Guyana as the countries with the highest prevalence ratios. Cuba $(0.1 \%)$ and Puerto Rico (less than $1 \%$ ) have the lowest rates of the Caribbean area. These figures, however, are considered inadequate because surveillance is not consistent enough to capture changes of the epidemic over time, so there is a strong suspicion of underestimation in prevalence levels. Heterosexual sex seems to be the main vehicle of transmission of the HIV infection in the Caribbean, but due to rampant homophobia, underreporting MSM HIV cases are also suspected. This pandemic is boosted by poverty, gender inequalities, stigma and strong migration flows.

A wide range of strategies have been put into practice across nations in different capacities, such as condom distribution, harm-reduction programs (provision of clean needles and drug-addiction clinics), voluntary counseling and testing, preventing mother-to-child-transmission, media campaigns, sex education in schools, and the like. Nevertheless, due to lack of consistency in HIV prevention policies and poor sero-surveillance practices among the general population, there is a suspicion that the epidemic remains heavily underestimated and conditions may change suddenly.

According to Avert, a British think tank, HIV prevention efforts in Latin America have been small scale, slow and largely dependent upon non-governmental organizations and international programs. This statement may be sustained by the USAID report showing HIV/AIDS as the leading cause of death among adults, followed by cardio-vascular diseases. Prevention efforts have been particularly strong in Brazil, Mexico and Belize through television, billboards, posters, condom distribution, harm-reduction programs for injecting drug users, and sex education. Many Latin American countries have developed national AIDS commissions, as well as a body of legislation protecting the rights of those infected with the virus and strategic plans, at least in paper. Scarcity of resources to achieve these goals together with strong economic downturns during the 1990's and 2000's has delayed the accomplishment of these efforts.

Besides the domestic responses to the HIV epidemic throughout the region, industrial nations have also implemented several prevention and treatment strategies for Latin American countries, funded with public and private resources. The United States government has been instrumental in the fight against the disease in the region and currently have two main sources of funding to provide assistance to several countries: a) one is achieved through the President's Emergency Plan for AIDS Relief (PEPFAR) supporting activities in Haiti and Guyana, two of the nations heavily affected by the epidemic, and b) another is the Agency for International Development (USAID) with important HIV agendas in several countries and some regional programs. The Pan Caribbean Partnership Against HIV/AIDS (PANCAP) is a coordinated response of governments, non-government organizations, private sector groups and donor agencies to implement prevention and treatment efforts in the Caribbean to lessen the negative effects of the pandemic.

This study states that as HIV prevalence increases and the number of cases at a point in time turns out to be sizeable, the impact of the disease on the economic and social fabric becomes more apparent. In Latin American countries, HIV prevalence has remained unchanged for the past years suggesting that the epidemic has not affected economic performance but without the proper set of intervention strategies it can get out of control and these numbers may rise unexpectedly. Latin America countries have the opportunity to avoid the devastating effects of the HIV/AIDS epidemic if sound and timely policies are implemented in order to improve their economic structure, institutions and healthcare systems. Foreign aid arises as a possible policy recommendation to ameliorate this potential risk.

\section{Data and Econometric Analysis}

In the neoclassical growth model, the rate of growth of per capita income tends to be related to a wide number of factors whose relationship have been well established in the empirical literature on growth (Mankiw, Romer and Weil, 1992; Islam, 1995; McDonald, 200x). This analysis is recognized in the vast literature seeking associations between the long-run growth rates and a variety of economic, political, institutional epidemiological and socio-cultural factors. In this context, a growth equation assessing the impact of HIV on the economy has to be 
estimated as a system of equations including the determinants of growth and HIV prevalence for selected Latin American economies.

To quantitatively identify and measure the effect of HIV epidemic in the growth rate, statistical analysis is necessary. Socio-economic as well as epidemiological information over the past two decades was compiled. The idea is to establish the relationship between the HIV incidence and the most relevant determinants of economic performance. As the data set compiled contains measurements on country-specific conditions over the years, it combines characteristics of both cross-sectional and time series data. As pointed by Hsiao (1985), a panel data set "allows economists and other social scientists to analyze, in depth, complex economic and related issues which could not have been treated with equal rigor using time series or cross-sectional data alone”. It is suitable to cast the analyses into the framework of dynamic panel data models, which allow us great flexibility in modeling differences across countries in this sample.

Panel data allow us to control for unobservable variables such as dynamic factors and variables that change over years but not across countries. Panel data also allow us to better understand the dynamics of the relationship between the HIV incidence and underlying determinants. A panel examination is necessary to capture changes of the variables under consideration across countries and over time. In its most simple form, a panel regression analysis is a method of studying a particular subject within multiple sites, periodically observed over a define time frame. With repeated observations of enough cross-sections, panel data permits the researcher to study the dynamics of change with short time series.

Even though there are a sizeable number of AIDS cases in Latin America at the beginning of the 1980's, this paper only analyzes information between 1998 and 2006 for a cross-section of 19 countries for which data on HIV prevalence, per capita gross domestic product, productivity levels, income inequality (Gini Coefficient ), degree of openness and components of expenditures were found. In the historical path of the HIV/AIDS epidemic, the illness shifted from being a matter of public health during the late 1980's to become a matter of economic dynamic in the early 1990's. Our panel data analysis is a collection of 19 Latin American and Caribbean countries for which there is information of the same economic and health variables (HIV prevalence and infant mortality rates) that were collected for 9 years.

This time series cross sectional data contains a total of 171 observations where the sources for socio-economic variables are the Center for International Comparisons of Production, Income and Prices of the University of Pennsylvania and the Human Development Report of the World Bank. Time series for HIV prevalence and infant mortality rates were obtained from the Joint United Nations Programme on HIV/AIDS (UNAIDS) and the World Health Organization (WHO). Life expectancy data was collected from World Bank’s World Development Indicators.

Our data have a temporal reference, $t$, in this case for a year, and a cross sectional unit of observation, which in this case is country $i$. The error term captures these two dimensions, one for the country and one for the period. As there are no missing values, the data is a balanced panel. To achieve our goal of capturing changes of the HIV epidemic across countries over time, a fixed effect model, also known as the least squares dummy variable model, is required. This is an unobserved effect panel data where the unobserved effect can be arbitrarily correlated with the explanatory variable in each time period (Wooldridge, 2001).

$$
\mathrm{Y}_{\text {it }}=\beta \mathrm{HIV}_{\text {it }}+\gamma \mathrm{X}_{\text {it }}+\alpha_{i}+\varepsilon_{\text {it }}
$$

This empirical equation shows per capita income (Y) as a function of a health determinant (HIV prevalence) and controlled by a matrix $\mathrm{X}$ of well-identified variables influencing growth such as the share of private investment, government spending, and consumption as well as population growth and degree of openness. In this specification, the subscript i represents a country and t stands for the time; is the coefficient that need to be estimated. Finally, follows a one-way (country-specific effect) or two-way (individual-specific effect) error component model.

Many economic variables such as income exhibit trending behavior and their estimations may generate an spurious regression, unless they are co-integrated. A common trend removal or de-trending procedures are the first and second differencing regression, which in the report, this statistics is named $\mathrm{D}(\mathrm{HIV}, \mathrm{N})$. A useful approach to determine whether differentiation should be applied is known as the unit root test, which resolves the pair of variables to exhibit mean-reverting behavior. In a series of panel regressions, the HIV prevalence showed the expected sign during the first and second differentiation; however, statistically speaking, these markers are not significantly different from zero. 


\section{Empirical Results and Policy Implications}

This study uses a sample of 19 selected Latin American countries chosen based on the availability of information to build the data set, which comes from the World Development Indicators (World Bank) and Human Development Report (UNDP, 2006). Per capita gross domestic product and other macroeconomic indicators were built using information from Heston et al. (2006) data set (Penn World Table Version 6.3, Center for International Comparisons of Production). Other relevant data that matched economic and socio-demographic figures were found also in the Human Development Report (UNDP), the World Development Indicators (World Bank), World Mortality Report (UNPD, 2006), and the Population, Resources, Environment and Development: The 2005 Revision (UNDP). The HIV/AIDS prevalence estimates were obtained using information from the 2009 Report on the Global AIDS Epidemic (WHO/UNAIDS) and the Human Development Report (UNDP, 2006).

The sample of countries used in this study shows great variations in terms of population and income per capita (see table 1 and 2). The most populated country is Brazil and the least is Belize, with a mean value of 26.6 million and a standard deviation of 47.8 million. The real gross domestic income per capita, adjusted for terms of trade changes, also varies across countries where the highest value corresponds to Chile and the lowest to Nicaragua showing an average of $\$ 8,319$ with a standard deviation of $\$ 4,648$ for the overall sample of countries.

The choice of the sample does not capture income inequalities, which are indeed a common problem in Latin America. In this region the allocation of wealth, consumption levels, access to education, health as well as other socio-economic variables has been historically unevenly distributed. The Gini Coefficient is 0.530 across the countries of our sample, not far away from the estimated for the entire world, which lies between 0.560 and 0.660, according to the 2003 Human Development Report.

\section{$<$ Table 1 and $2>$}

There are mixed signals regarding the HIV/AIDS epidemic in Latin America, boosted in part by the fact that it has not reached the high levels as in Sub-Saharan Africa. Consequently, some leaders and policy-makers may believe that there is not risk associated with the loss of human capital. As said before, country-specific conditions play an important role in the explanation of the path that the local epidemics have followed in the past decade. Although the HIV infection has become one of top leading causes of death among men and women during the first half of last decade, evidence release by UNAIDS shows that the epidemic has stabilized in the past years.

While it is very hard to generalize on the natural history of the HIV epidemic, there are several common denominators characterizing it across Latin American countries such as pronounced business cycles, increasing gap in income inequality, inefficient health care systems, large migration flows, and differences in the progression of the epidemic across countries. The lack of reaction in several nations has been rooted in cultural and societal values, such as homophobia, discrimination, and stigma towards people living with the HIV infection. There are worrisome signs that the disease is moving slowly but consistently from being concentrated among high-risk groups to becoming generalized in the entire population (DelaCruz, 2010).

Regarding our econometric devise, different tests confirmed that fixed effects are the appropriate specification in this particular case. Where country specific effects are required, the panel data model is estimated using the appropriate technique (McDonald, 2004). Table 3 captures the effect of HIV prevalence on the growth rate of per capita income controlling for well-known determinants of economic performance, such as private and public investment, degree of openness and a measure of human capital (HIV prevalence in this study). In this arrangement, GDP per capita is inversely determined by the rate of growth of the labor force (as expected) and public spending (wrong sign) but positively related to private investments; however, the first derivative of the level of the HIV epidemic seems to be insignificantly different from zero and provides no evidence of influence on income per capita. The absence of significance is disappointing but may suggest that the HIV epidemic is still concentrated in high-risky groups such as men having sex with men, sex workers or injecting-drug users or the existence of underreported cases of morbid-mortality.

\section{$<$ Table 3 and $4>$}

Second differencing removes the time invariant country specific effects producing an equation that can be estimated (see results in table 4). In this regression, the rate of growth of labor force (measured by population increases) and public expenditures is again negatively related with the growth rate of per capita income. Also, per capita income seems to be positively associated with consumption, which supports the idea that the HIV epidemic has not affected disposable income through the diversion of higher expenditure in medication or health items related to HIV/AIDS. 
In both regressions, the measure for health (HIV) exhibits the expected negative sign but is insignificant, sustaining the lack of evidence of any mechanism of transmission of HIV on labor productivity and economic performance. Surprisingly, the right-hand side variables explain in great extent the dependent variable by almost $30 \%$ and the F-statistic makes the whole regression very reliable. These findings are consistent with the view that when the HIV epidemic is low, there are normal economic expectations and the burden of the disease is not carrying great weight (Dixon, 2001).

Rapid demographic, epidemiological, and socio-economic changes have caused the virus' spread in several countries of Africa, Central Asia, Eastern Europe and Latin America. The HIV epidemic has been particularly receptive to large movement of people across borders, warfare, economic cycles and other drastic variations in the social fabric. The nature of the epidemic responds to some factors such as circumcision and ethnic diversity, which in fact seems to be good predictors of the course of the illness, as demonstrated in previous work (DelaCruz, 2010). Sub-Saharan Africa has been the region most hardly hit by this epidemic and its influence in the economic sphere has become evident

In terms of the individual health policies, uneven responses have occurred throughout the region, with some countries displaying weak political leadership and others, like Brazil, forming strong and positive accomplishments. HIV transmission is manifold and depends on biological, socio-cultural and behavioral factors, therefore prevention efforts should include not only cost-effective or cost-efficiency methods but also strategies to promote changes in behavior in order to lower the effects of the epidemic in the long-run. Even though evidence suggests that the epidemic is still low and concentrated among certain groups, the lack of reliable information makes difficult to determine whether this decline has to do with the natural course of the epidemic or the success of prevention practices.

\section{Conclusions}

A panel regression was implemented to evaluate the impact of the HIV epidemic on economic growth in selected nations of Latin America. The result of this appraisal does not provide support to our original hypothesis that the HIV/AIDS epidemic has worsened economic performance during the period analyzed within the sample of countries, probably due to the low levels of the epidemic. However, the HIV infection is relevant because there are worrying signs suggesting that these nations may be moving towards relatively higher levels of HIV prevalence rapidly.

A plausible explanation is that the disease is both concentrated among risky-behavior groups and also have characteristics of the generalized epidemic, so to speak women getting infected at faster rates (reduction in size of the male to female ratio). Even in low prevalence countries the situation can change rapidly with devastating consequences as occurred in other places such as in Nepal and Indonesia. The extent of government intervention and the social cost of delaying action to fight the HIV/AIDS epidemic are some of the main concerns connected to this problem.

Although governments have been able to use more sophisticated techniques to monitor HIV prevalence across Latin A, these systems need to be improved in order to provide more reliability to predict the path of the epidemic and propose policy measures in order to avoid its future explosion. Furthermore, there is a gap in testing, treatment and prevention efforts to assure a decrease in HIV prevalence in the coming years, therefore the future of the epidemic remains uncertain.

Traditional prevention policies such as media campaigns, condom distribution and harm-reduction programs have contributed to the stabilization of the epidemic in the short run but seem to fall short in the growing importance of the epidemic in the national health systems because of a weak public infrastructure and human capacity. Raising a greater level of awareness about HIV, increasing the size of foreign aid to less developed countries, reducing stigmatization of the disease, improving testing procedures and erecting a more comprehensive health care system seem to be some of the most effective strategies to control the HIV epidemic in the region in the long run. 


\section{References}

AIDS Epidemic Update. (2006). The Joint United Nation Program on HIV/AIDS, December (06/29E).

AIDS Epidemic Update. (2006). The Joint United Nation Program on HIV/AIDS, December 2006 (06/29E).

Barro, R. (1996). Health and Economic Growth, Pan American Health Organization, Division of Health and Human Development, Series Health, Human Capital and Economic Growth.

Barro, R. \& Lee, J. (1993). International comparisons of educational attainments, Journal of Monetary Economics, 32, 363-394. http://dx.doi.org/10.1016\%2F0304-3932\%2893\%2990023-9

Barro, R. \& Lee, J. (2000). International data on educational attainments: updates and implications. Working Paper, No. 42. Center for International Development, Harvard University, May.

Bonnel, R. (2000). HIV/AIDS. Does It Increase or Decrease Growth in Africa? World Bank, ACT Africa, November.

Cuddington, J. (1993). Modeling the macroeconomic effects of AIDS, with an application to Tanzania. World Bank Economic Review, 7 (3), 173-189. http://dx.doi.org/10.1093\%2Fwber\%2F7.2.173

Cuddington, J. \& Hancock, J. (1994). Assessing the impact of AIDS on the growth path of the Malawian economy, Journal of Development Economics, 43, 363-368. http://dx.doi.org/10.1016/0304-3878(94)90013-2

David, Antonio C. (2007). HIV/AIDS and Social Capital in a Cross-Section of Countries, World Bank, Policy Research Working Papers, 4263, June 2007.

De Walque, D. (2006). Who gets AIDS and how? The determinants of HIV infection and sexual behaviors in Burkina Faso, Cameroon, Ghana, Kenya and Tanzania, World Bank Policy Research Working Paper, 3844, February.

DelaCruz, Juan. (2010). The Economic Impact of the HIV/AIDS Epidemic across Countries: Factors Explaining the Spread of the Disease, VDM Publishers, Saarbrucken, Germany, 2010.

Dixon, S., McDonald, S., \& Roberts, J. (2001). AIDS and Economic Growth in Africa: A Panel Data Analysis, Journal of International Development, 13, 411-426. http://dx.doi.org/10.1002\%2Fjid.795

Dixon, S., McDonald, S., \& Roberts, J. (2001). AIDS and economic growth in Africa: a panel data analysis, Journal of International Development, 13, 411-426.

Franko, Patrice. (2007). The Puzzle of Latin American Economic Development. Rowman \& Littlefield Publishers, Third Edition, UK.

Garcia, A. et al. (2003). HIV/AIDS in Latin American Countries: The Challenge Ahead. World Bank, Health, Nutrition, and Population Series, Washington.

Garcia, A. et al. (2003). HIV/AIDS in Latin American countries: The challenge ahead. World Bank, Health, Nutrition, and Population Series, Washington.

Hsiao, C. (1985). Benefits and Limitations of Panel Data. Econometric Reviews, 4 (1), 121-174. http://dx.doi.org/10.1080\%2F07474938508800078

Islam, N. (1995). Growth empirics: a panel data approach, The Quarterly Journal of Economics, 110 (4), 1127-1170. http://dx.doi.org/10.2307\%2F2946651

Jenkins, C. \& Robalino, D. (2003). HIV/AIDS in the Middle East and North Africa: The Cost of Inaction. World Bank, Orientation in Development Series, 2003.

Jenkins, C. \& Robalino, D. (2003). HIV/AIDS in the Middle East and North Africa: The cost of inaction. Orientation in Development Series. World Bank.

Knowles, S. \& Owen, D. (1995). Health capital and cross-country variation in income per capita in the Mankiw-Romer-Weil model. Economics Letters, $48 \quad$ (1), 99-106. http://dx.doi.org/10.1016\%2F0165-1765\%2894\%2900577-O

Levine, R. \& Renelt, D. (1992). A sensitivity analysis of cross-country growth regressions, The American Economic Review, September, 82 (4), 942-963.

Mankiw, G., Romer, D., \& Weil, D. (1992). A contribution to the empirics of economic growth. Quarterly Journal of Economics, 107 (2), 407-437. http://dx.doi.org/10.2307/2118477

McDonald, S. \& Roberts, J. (2002). Growth and multiple form of human capital in an augmented Solow model: 
a panel data investigation. Economics Letters, 74, 271-276. http://dx.doi.org/10.1016/S0165-1765(01)00539-0

McDonald, S. \& Roberts, J. (2004). AIDS and economic growth: a human capital approach. Sheffield Economic Research Paper Series. No. 2004008. http://dx.doi.org/10.1016/j.jdeveco.2005.01.004

Rebelo, S. (1991). Long-run policy analysis and long-run growth. Journal of Political Economy, 99, 500-521. http://dx.doi.org/10.1086/261764

Robalino, D., et al. (2002). Risks and Macro-Economic Impacts of HIV/AIDS in the Middle East and North Africa: why waiting to Intervene can be costly. The World Bank Working Paper, Series 26.

Robalino, D., et al. (2002). Risks and macro-economic impacts of HIV/AIDS in the Middle East and North Africa: why waiting to intervene can be costly. Working Paper Series 26, The World Bank, July.

Shastry, G. \& Weil, D. (2003). How much of cross-country income variation is explained by health? Journal of the European Economic Association, 1 (2-3), 387-396. http://dx.doi.org/10.1162/154247603322391026

Suarez-B, Ruben. (2000). Health System Inequalities and Inequities in Latin America and the Caribbean: Findings and Policy Implications. World Bank/PAHO, Working Document, December 2000.

UNAIDS/WHO. (2006). 2006 report on the Global AIDS epidemic.

United Nations Development Program (UNDP). (2006). Beyond scarcity: power, poverty and the global water crisis. The Human Development Report, United Nations Population Division (UNPD).

United Nations Population Division (UNPD). (2005). World Mortality Report, Department of Economic and Social Affairs, United Nations Population Division (UNPD).

Werker, E. et al. (2006). Male Circumcision and AIDS: the Macroeconomic Impact of a Health Crisis, Harvard School of Business. Working Paper, No. 07-025.

Winkler, C., et al. (2004). Patterns of ethnic diversity among the genes that influence AIDS. Human Molecular Genetics Review, 13 (1). http://dx.doi.org/10.1093/hmg/ddh075

Wooldridge, J. M. (2001). Econometric Analysis of Cross Section and Panel Data, MIT Press, First Edition.

World Bank (1993). World Development Report 1993: investing in health, World Bank/Oxford University Press, June.

World Health Organization (WHO). (2001). Investing in health for economic development: report of the Commission on Macroeconomics and Health. World Health Organization, Geneva.

APPENDIX 1 (Source: http://www.avert.org/aids-statistics.htm)Both tables: Millions of people in 2008

${ }^{*}$ In millions ${ }^{a}=$ People Living With HIV/AIDS ${ }^{b}=$ Proportion of adults aged 15-49 who were living with HIV/AIDS

a) Worldwide AIDS Statistics

\begin{tabular}{|l|l|l|}
\hline & Estimate & Range \\
\hline People living with HIV/AIDS & 33.400 & $31.1-35.8$ \\
\hline Adults living with HIV/AIDS & 31.300 & $29.2-33.7$ \\
\hline Women living with HIV/AIDS & 15.700 & $14.2-17.2$ \\
\hline Children living with HIV/AIDS & 2.100 & $1.2-2.9$ \\
\hline People newly infected with HIV & 2.700 & $2.4-3.0$ \\
\hline Children newly infected with HIV & 0.430 & $0.24-0.61$ \\
\hline AIDS deaths & 2.000 & $1.7-2.4$ \\
\hline Child AIDS deaths & 0.280 & $0.15-0.41$ \\
\hline
\end{tabular}


b) Regional AIDS Statistics

\begin{tabular}{|l|l|l|l|l|}
\hline & PLWH $^{*}$ & Newly Infec & HIV Prevalence & Deaths* $^{*}$ \\
\hline Sub-Saharan Africa & 22.400 & 1.900 & $5.20 \%$ & 1.400 \\
\hline North Africa \& Middle East & 0.310 & 0.035 & $0.20 \%$ & 0.020 \\
\hline South and South-East Asia & 3.800 & 0.280 & $0.30 \%$ & 0.270 \\
\hline East Asia & 0.850 & 0.075 & $<0.1 \%$ & 0.059 \\
\hline Oceania & 0.059 & 0.004 & $0.30 \%$ & 0.002 \\
\hline Latin America & 2.000 & 0.170 & $0.60 \%$ & 0.077 \\
\hline Caribbean & 0.240 & 0.020 & $1.00 \%$ & 0.012 \\
\hline Eastern Europe \& Central Asia & 1.500 & 0.110 & $0.70 \%$ & 0.087 \\
\hline North America & 1.400 & 0.055 & $0.40 \%$ & 0.025 \\
\hline Western \& Central Europe & 0.850 & 0.030 & $0.30 \%$ & 0.013 \\
\hline Global Total & 33.400 & 2.700 & $0.80 \%$ & 2.000 \\
\hline
\end{tabular}

Table 1. Basic Statistics

\begin{tabular}{|l|r|r|r|r|}
\hline & \multicolumn{1}{|c|}{ Population* } & GDP Per Capita & Income Inequality & HIV Prevalence** \\
\hline Mean & $26,697.12$ & $8,319.32$ & 0.530 & 0.795 \\
\hline Maximum & $193,918.58$ & $20,242.09$ & 0.616 & 2.500 \\
\hline Minimum & 294.61 & $2,172.48$ & 0.432 & 0.059 \\
\hline Stand Dev & $47,841.33$ & $4,648.02$ & 0.706 \\
\hline$*$ In thousands & $* *$ Per 1,000 adults between 14 and 49 years old \\
\hline
\end{tabular}


Table 2. Socio-Economic Indicators in Selected Economies

\begin{tabular}{|c|c|c|c|c|c|c|c|}
\hline Country & Population & $\begin{array}{l}\text { Per Capita } \\
\text { GDP }\end{array}$ & Openness & Consumption & Government & Investment & $\begin{array}{l}\text { Gini } \\
\text { Coef. }\end{array}$ \\
\hline Argentina & 40048.82 & 15536.25 & 47.38 & 63.80 & 12.28 & 21.58 & 0.46 \\
\hline Belize & 294.61 & 9286.36 & 122.29 & 64.16 & 14.62 & 20.27 & 0.55 \\
\hline Bolivia & 9425.94 & 3878.71 & 69.26 & 71.78 & 13.70 & 9.44 & 0.59 \\
\hline Brazil & 193918.58 & 9504.81 & 24.71 & 64.20 & 18.48 & 14.18 & 0.61 \\
\hline Chile & 16303.85 & 20242.09 & 80.09 & 54.80 & 12.16 & 28.02 & 0.57 \\
\hline Colombia & 44379.60 & 7897.59 & 51.22 & 65.78 & 19.36 & 21.42 & 0.54 \\
\hline Costa Rica & 4137.37 & 11609.35 & 104.65 & 58.86 & 13.94 & 29.38 & 0.46 \\
\hline Ecuador & 14134.96 & 6130.52 & 64.58 & 65.26 & 14.86 & 23.83 & 0.51 \\
\hline El Salvador & 6948.07 & 5585.08 & 75.64 & 89.25 & 12.77 & 19.13 & 0.53 \\
\hline Guatemala & 12728.11 & 6071.09 & 68.24 & 79.68 & 12.55 & 23.96 & 0.56 \\
\hline Guyana & 769.10 & 2455.65 & 205.93 & 63.57 & 34.05 & 25.24 & 0.43 \\
\hline Honduras & 7483.76 & 3576.30 & 129.12 & 66.98 & 21.23 & 34.55 & 0.56 \\
\hline Mexico & 108700.89 & 11310.57 & 67.49 & 66.20 & 11.39 & 25.22 & 0.53 \\
\hline Nicaragua & 5680.21 & 2172.48 & 95.49 & 73.76 & 23.84 & 32.03 & 0.60 \\
\hline Panama & 3258.33 & 8914.94 & 148.79 & 52.26 & 14.72 & 24.83 & 0.49 \\
\hline Paraguay & 6669.09 & 4642.05 & 138.80 & 71.88 & 17.49 & 12.78 & 0.58 \\
\hline Peru & 28432.59 & 6424.53 & 43.70 & 62.55 & 12.61 & 21.47 & 0.46 \\
\hline Suriname & 470.78 & 9996.88 & 118.50 & 16.01 & 7.69 & 84.21 & 0.62 \\
\hline Uruguay & 3460.61 & 12831.83 & 63.13 & 71.97 & 11.71 & 16.31 & 0.45 \\
\hline \multicolumn{8}{|c|}{ Source: Center for International Comparisons of Production, Income and Prices, University of Pennsylvania, } \\
\hline
\end{tabular}


Table 3. Growth Rate of Per Capita Income and HIV Prevalence Panel Least Squares

Cross-sections included: 19 Period: 1998-2006

\begin{tabular}{|l|c|}
\hline & Regression Coefficient \\
\hline Constant Term & $14.90329(10.8084)$ \\
\hline Population Growth & $-9.52709^{*}(3.14246)$ \\
\hline D (HIVN) + & $-0.000107(0.00014)$ \\
\hline Private Consumption & $0.058179(0.15135)$ \\
\hline Public Spending & $-0.869509^{* *}(0.39933)$ \\
\hline Private Investments & $0.228924^{* *}(0.1143)$ \\
\hline Degree of Openness & $0.082877(0.06095)$ \\
\hline R-Square $=0.2923$ & SE of Regression= 4.3371 \\
Durbin-Watson stat $=1.717$ & Akaike info criterion $=5.921$ \\
F-statistic $=2.1863$ & Prob (F-statistic $)=0.0028$ \\
\hline
\end{tabular}

+ First Derivative of HIV Prevalence

Table 4. Growth Rate of Per Capita Income and HIV Prevalence Panel Least Squares

Cross-sections included: 19 Period: 1998-2006

\begin{tabular}{|l|c|}
\hline & Regression Coefficient \\
\hline Constant Term & $19.45332(10.6644)$ \\
\hline Population Growth & $-5.818382^{* *}(2.97200)$ \\
\hline D (HIVN,2) ++ & $-0.000078(0.000079)$ \\
\hline Private Consumption & $0.256848^{* * *}(0.14960)$ \\
\hline Public Spending & $-1.828307^{*}(0.46693)$ \\
\hline Private Investments & $0.128014(0.11877)$ \\
\hline Degree of Openness & $0.020284(0.05597)$ \\
\hline R-Square = 0.2923 & SE of Regression= 4.3371 \\
Durbin-Watson stat $=1.717$ & Akaike info criterion= 5.921 \\
F-statistic $=2.1863$ & Prob (F-statistic $)=0.0028$ \\
\hline
\end{tabular}

++ Second Derivative of HIV Prevalence

(Robust Standard Errors in parenthesis) * Significant at 0.01, ** Significant at 0.05 and *** Significant at 0.10 


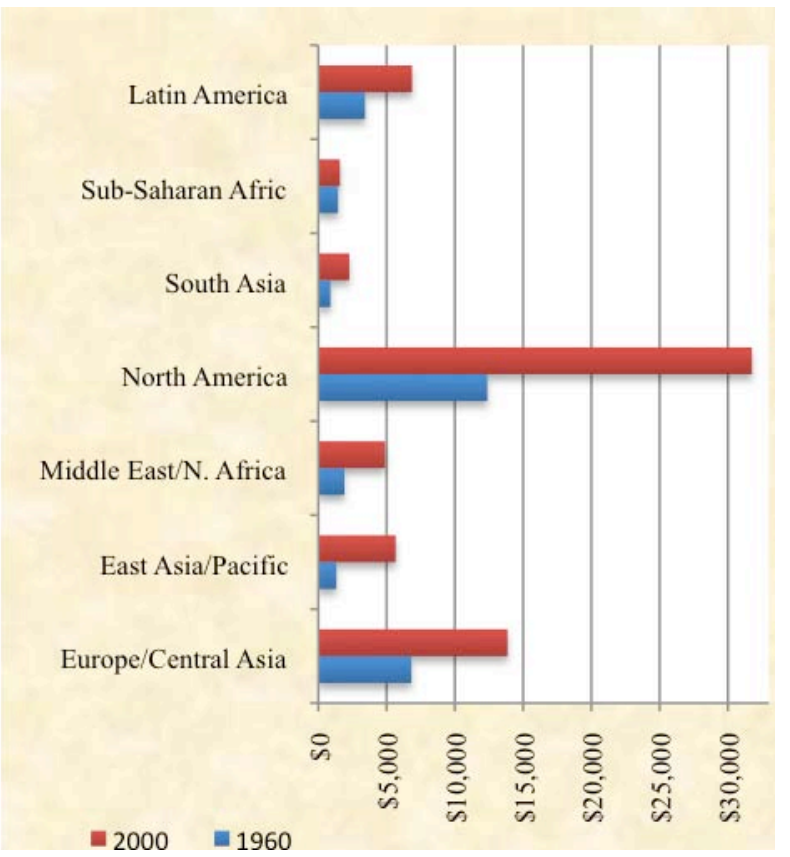

Figure 1. Income Per Capita (1960 and 2000)*

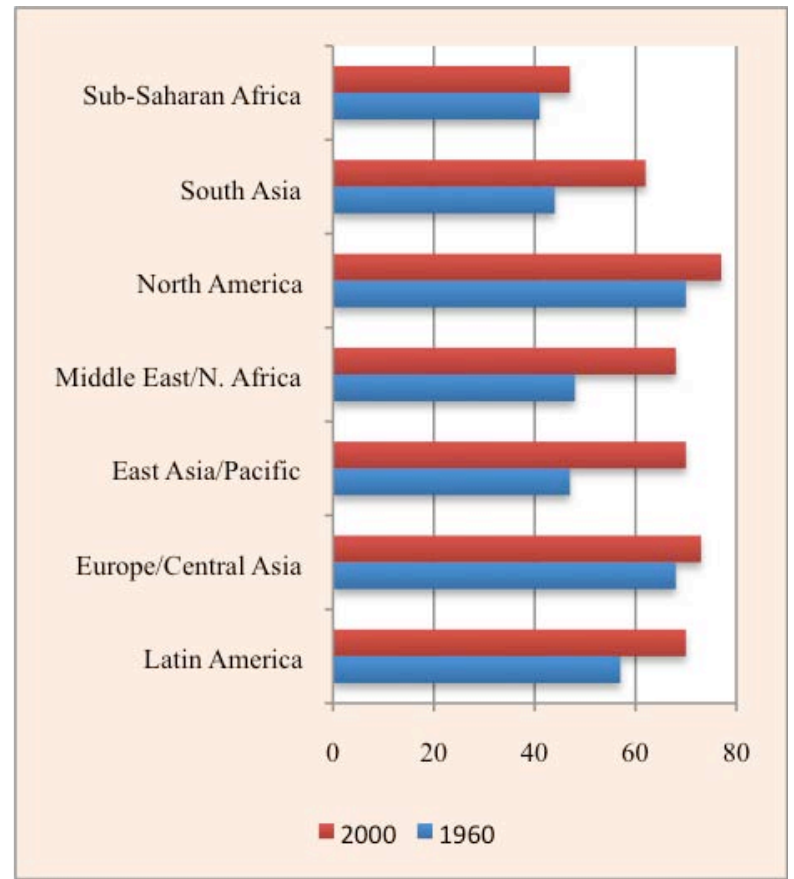

Figure 2. Life Expectancy (1960 and 2000)*

* Source: World Development Indicators, World Bank (http://data.worldbank.org/indicator)

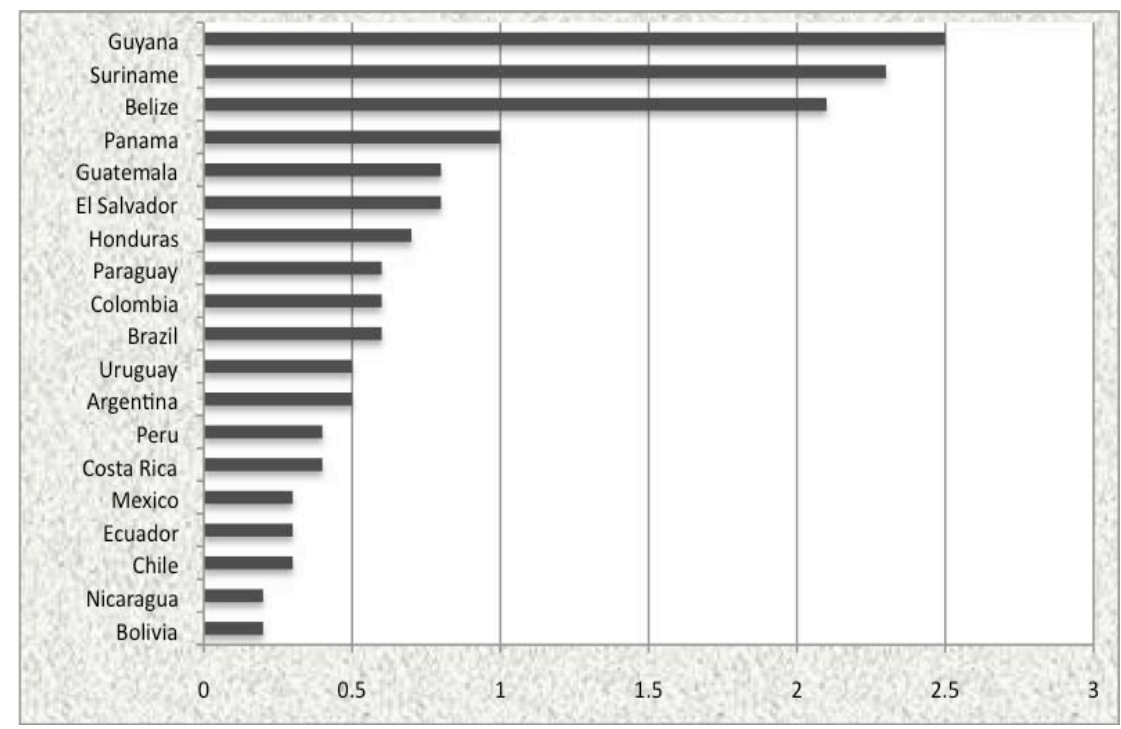

Figure 3. HIV Prevalence in Selected Countries Source: UNAIDS*

http://www.unaids.org/en/dataanalysis/epidemiology/2008reportontheglobalaidsepidemic/ 